\title{
Problems Faced by Secondary Technology Education Novice and Veteran Teachers
}

\author{
Sally E. Arnett-Hartwick ${ }^{\mathrm{a}}$, John Cannon ${ }^{\mathrm{b}}$ \\ ${ }^{a}$ Illinois State University, ${ }^{b}$ University of Idaho
}

\begin{abstract}
The purpose of this study was to examine the challenges faced by secondary technology education (TE) teachers in Illinois. Specifically, the study sought to identify and categorize a list of challenges encountered during their first years in the TE profession as well as challenges that veteran TE teachers are facing in their current teaching assignment. Seventy-three TE teachers completed an online questionnaire. Twenty-six challenges were identified and of the top five challenges, only three, equipment, funding, and understanding what TE is were identified as a continuous challenge at each career stage. Knowing the challenges identified by TE teachers at different career stages can assist school administration and TE professionals in providing specific support to address these problematic areas in efforts to improve retention rates among TE teachers.
\end{abstract}

Keywords: technology education teachers, teacher education teacher problems, teacher career stage problems

Industrial occupations, also known as technology education (TE), and part of the science, technology, engineering, and mathematics career cluster, was identified as a teacher shortage area in many states for the 2017-2018 school year (Cross, 2017). Teacher retirement and attrition have been identified as two main problems for the increased need of TE educators over the past 10 to 15 years (Gaytan, 2005). Retirement is an inevitable reason for TE teachers to leave the classroom; however, the reasons teachers choose to leave the classroom early are often linked to the number and types of problems they face (Boone \& Boone, 2007).

One way to increase the number of TE teachers is to decrease the number who leave through attrition. However, outdated evidence exists on the retention and challenges of TE teachers. Therefore, the purpose of this study was to examine the problems faced by all secondary TE teachers in Illinois. A crucial first step to preserve the future of the profession is to gather empirical data that accurately identifies the current challenges facing TE teachers. An understanding of the concerns of teachers at different stages in their careers allows TE professionals and school administrators to identify more specific ways to provide support. This in turn could improve the retention rates among TE teachers.

(i) $\odot$ Creative Commons CC-BY-NC-ND: This article is distributed under the terms of the Creative Commons Attribution 4.0 License (http://creativecommons.org/licenses/by/4.0/) which allows others to download your works and share them with others as long as they credit you, but they can't change them in any way or use them commercially. 


\section{Review of Literature}

Attrition and Reasons for Leaving. Attrition among teachers has been the single largest factor determining the demand for additional teachers in all subjects in the United States (Clandinin \& Long, 2015). In fact, many teachers leave the classroom within the first five years (Tamberg, 2006). Specific to Illinois, $60 \%$ of school districts reported difficulty filling positions and $16 \%$ had to cancel programs or classes because of teacher shortages (Illinois Association of Regional Superintendents of Schools, 2016). The reason many have exited the teaching profession was due to education-related problems; thus, the ability to handle the challenges faced can result in a teacher staying or leaving the classroom.

Problems faced by teachers are quite extensive. Frequently reported problems for teachers were classroom management, motivating students, insufficient supplies, time management, funding, facilities, equipment, lack of administrative support, school policy and procedures, and inadequate mentorship programs (Heath-Camp, Camp, AdamsCasmus, Talbert, \& Barber, 1992; Gaytan, 2005; Hughes, 2012; Johnson, 2004; Stair, Warner, \& Moore, 2010). Career and technical education (CTE) researchers have identified motivating students to learn, classroom management, using technology as a teaching tool, and assisting students to increase critical thinking skills as professional development needs (Cannon, Kitchel, Duncan, \& Arnett, 2011; Duncan, Ricketts, Peak, \& Uesseler, 2006; Joerger, 2002; Layfield \& Dobbins, 2002). Although the problems identified above are true for teachers, are they also true for the subgroup of TE teachers?

Problems. Teaching in CTE, of which TE is a service area, is a rigorous yet frequently underrated challenge (Cushall, 2002). The American Federation of Teachers (AFT) (2014) studied the concerns among CTE teachers as a whole and found that space, equipment, technology, and funding were the dominant challenges noted. Other challenges identified were establishing partner and community connections, management constraints, class sizes, student motivation, unreasonable expectations by administrators, and time to learn or update knowledge on new equipment or software. Most recently, Advance CTE (2016) noted that competition with industry work, financial incentives, and the need for educating the community about the true nature of CTE curricula, were additional challenges faced by today's all CTE educators.

Specifically with TE, Wicklein (1993) indicated the top five problems facing the profession were inadequate marketing and public relations of TE, lack of consensus of curriculum content for $\mathrm{TE}$, teacher resistance to changes within TE, inaccurate understanding and support of TE by administrators and counselors, and inadequate financial support for TE. Over a decade later, Wicklein (2004) asked TE professionals, including middle and high school teachers, university teacher educators, and supervisors, to rate and rank the pre-identified problems that were found in the previous study. TE educators ranked insufficient supply of available TE teachers as the most pressing problem followed by marginal understanding by administrators and counselors, lack of understanding by the general public, non-consensus of curriculum content, inadequate 
financial support, and increased graduation requirements impacting TE programming (Wicklein, 2004).

Mirroring Wicklein (2004), Lazaros and Rogers (2006) sought to determine if the same pre-identified problems were relevant among Indiana middle school and high school TE teachers. The findings indicated the most serious challenge was the impact of high school graduation requirements on enrollment in TE classes followed by the general public's lack of understanding of TE and funding for TE programs. Later, Lee (2009) contributed additional challenges as described by TE teachers that included outdated images, lack of administrative and parental support, and weak relationships with peer teachers. Although some research exists of the problems among TE teachers, as Wicklein (2004) recommended, problems and challenges among TE teachers need to be identified periodically to keep the profession aware of needs and pursue efforts to combat classroom departure.

Theoretical Framework. Career satisfaction has been identified as a determinant of a teacher's decision to remain or leave the profession (Ubom \& Joshua, 2004). Previous research indicated novice teachers expressed strong dissatisfaction as the primary reason they left jobs due to problems within teaching assignments (Voke, 2002). Self (2001) suggested that teachers resolve the question of whether to remain in education through "satisficing" rather than through optimizing. That is, the level of satisfaction was the rationale basis for a teacher leaving as opposed to trying to improve the situation.

The theoretical framework that has guided research related to job satisfaction has primarily focused on intrinsic and extrinsic factors. Garton and Robinson (2006) stated that the Motivation-Hygiene Theory centered on intrinsic and extrinsic factors could explain why teachers leave their positions.

Herzberg (1966) developed the Two-Factor Theory of Job Satisfaction, also known as the Motivation-Hygiene Theory. The central tenet of this theory is that job satisfaction and job dissatisfaction are influenced by two substantially different sets of work-related factors termed motivator and hygiene. Motivators are intrinsic factors of work while hygiene (maintenance) factors refer to extrinsic factors. Examples of motivator (intrinsic) factors include recognition, achievement, growth, and responsibility; whereas job instability, poor collegial relationships, and negative supervision are associated with hygiene (extrinsic) factors (Herzberg, 1966). Both motivator and hygiene factors have been reported to influence job satisfaction or dissatisfaction among teachers (Garton \& Robinson, 2006).

The Motivation-Hygiene theory operates on two mutually exclusive continuums (Figure 1). On the one hand, the job satisfaction continuum is impacted by motivator (intrinsic) factors and varies from a level of satisfaction to a level of no satisfaction. On the other hand, the job dissatisfaction continuum is impacted by hygiene (extrinsic) factors and operates from a level of dissatisfaction to a level of no dissatisfaction. Both motivator and hygiene factors, however, may prove to facilitate negative experiences in the classroom.

As applied to this study, if TE teachers encounter problems, they may be more likely to be isolated within their work environments, be nonparticipatory in school events, or discontinue their interest in their jobs. If so, teachers are more likely to leave the teaching profession and seek alternative types of employment due to dissatisfaction with the job 
Job Dissatisfaction

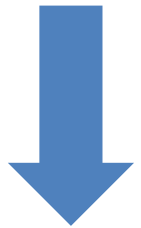

Influenced by Hygiene Factors

\section{Herzberg's Two-Factor Principles}

Job Satisfaction

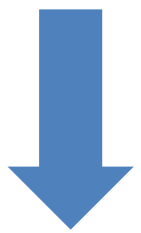

Improving the satisfier factors increases job satisfaction

\section{Influenced by Satisfier Factors}

Improving the hygiene factors

- Working Conditions

- Coworker relations

- Policies and rules

- Supervisor quality

- Base wage, salary

Figure 1. Model for Herzberg's (1966) Two-Factor Theory of Job Satisfaction, also known as the Motivation-Hygiene Theory

(Berns, 1990). For example, a TE teacher who has inadequate administrative support may become frustrated, which becomes a hygiene factor that would push the teacher to the negative end on the dissatisfaction continuum and, ultimately, may cause job dissatisfaction with perhaps a voluntary exit from teaching. Therefore, because job satisfaction is determined by intrinsic and extrinsic factors, understanding these categorical factors among novice and veteran TE teachers can prove beneficial for teacher retention.

\section{Method}

Purpose. The purpose of this study was to examine the problems faced by secondary TE teachers in Illinois. The primary objective was to identify and categorize a list of problems encountered by TE teachers during their first years in the education profession as well as problems faced by veteran TE teachers. The following research questions provided direction for the study:

1.What are the problems faced by novice TE teachers?

2.What are the problems faced by veteran TE teachers?

3.Are there differences in the problems faced by novice teachers and the problems faced by veteran teachers? 
Method and Procedures. A qualitative research design was selected to examine the phenomenon in detail and allow the respondents to describe the situations in their own words (Ary, Jacobs, Razavieh, \& Sorensen, 2006). IRB approval was received from the primary researcher's university before the study began. The population consisted of members of the secondary TE teachers association $(n=179)$ in Illinois during the 2018 school year.

A questionnaire adapted from Boone and Boone (2007) was used for this study. The questionnaire consisted of two open-ended questions. The first question asked respondents to describe two problems they encountered as a novice teacher in TE. The second question asked respondents to describe two problems they were currently facing. For this study, novice teachers were defined as teaching for four or fewer years. Veteran teachers were defined as teaching five or more years. Novice teachers were instructed to answer only the first open-ended question. The questionnaire was placed online using Qualtrics.

A cover letter that included the questionnaire link was emailed to every teacher in the accessible population. They were given one week to complete the questionnaire. Two subsequent weekly emails were sent to remind respondents to participate in the research study, as recommended by Dillman, Smyth, and Christian (2009). The return response rate was $39.6 \%$.

The response data from the two open-ended questions was divided into three stages for analysis. In stage one, the researcher transcribed the data. In stage two, the researcher and two other reviewers independently coded the data to establish themes; results were then compared for consensus to establish trustworthiness of the data. In the third stage, the data was summarized and interpreted (Ary et al., 2006).

\section{Findings}

The 73 respondents, which included 27 novice and 46 veteran TE teachers, provided responses to the open-ended questions. The majority of the respondents were male $(81 \%)$ and worked in a school located in a town (less than 3,000) $(37 \%)$ or suburbia $(30 \%)$. Data analysis produced 26 categories, which Table 1 ranks by frequency of novice teacher problems. The categories included equipment, funding, classroom management, image, variance in student abilities, reputation of previous teacher, student motivation, undergraduate preparation, curriculum issues, time management, administration support, number of class preps, enrollment numbers, faculty relationships, parents, paperwork, knowing policy and procedures, mentorships, guidance counselor issues, exceptional learners, professional development, job security, community support, student organizations, lab management, and understanding what TE is (Table 1).

Of the top five challenges, only three, equipment, funding, and understanding what TE is were identified as a continuous challenge at each career stage (Table 1). Respondents beginning their teaching career were most concerned with equipment, funding, discipline, understanding what TE is, and undergraduate preparation, whereas veteran respondents indicated they were most concerned with equipment, funding, class preps, administration support, and understanding what TE is. 
Journal of Research in Technical Careers

Table 1. Problems Experienced by Novice and Veteran TE Teachers

\begin{tabular}{lcccccc} 
& \multicolumn{2}{c}{ Novice Problem } & \multicolumn{3}{c}{ Veteran Problem } \\
\hline & Rank & $\mathrm{f}$ & $\%$ & Rank & $\mathrm{f}$ & $\%$ \\
\hline Equipment & 1 & 40 & 54.7 & 1 & 28 & 38.3 \\
Funding & 2 & 13 & 17.8 & 2 & 25 & 34.2 \\
Discipline & 3 & 10 & 13.6 & 6 & 4 & 8.2 \\
Understanding what TE is & 4 & 9 & 12.3 & 5 & 6 & 6.8 \\
Undergraduate preparation & 5 & 6 & 8.2 & 0 & 0 & 0 \\
Variance in student abilities & 6 & 5 & 6.8 & 6 & 4 & 5.4 \\
Reputation of previous teacher & 6 & 5 & 6.8 & 0 & 0 & 0.0 \\
Student motivation & 6 & 5 & 6.8 & 6 & 4 & 5.4 \\
Curriculum issues & 6 & 5 & 6.8 & 7 & 3 & 4.1 \\
Time management & 6 & 5 & 6.8 & 7 & 3 & 4.1 \\
Administration support & 7 & 4 & 5.4 & 4 & 8 & 10.9 \\
Class preps & 7 & 4 & 5.4 & 3 & 11 & 15.1 \\
Enrollment numbers & 8 & 3 & 4.1 & 7 & 3 & 4.1 \\
Faculty relationships & 8 & 3 & 4.1 & 9 & 1 & 1.4 \\
Parents & 9 & 2 & 4.1 & 0 & 0 & 0.0 \\
Paperwork & 9 & 2 & 2.7 & 0 & 0 & 0.0 \\
Knowing policies/procedures & 9 & 2 & 2.7 & 0 & 0 & 0.0 \\
Mentorships & 9 & 2 & 2.7 & 0 & 0 & 0.0 \\
Guidance counselor issues & 10 & 1 & 1.4 & 8 & 2 & 2.7 \\
Exceptional learners & 10 & 1 & 1.4 & 7 & 3 & 4.1 \\
Job security & 10 & 1 & 1.4 & 9 & 1 & 1.4 \\
Professional development & 10 & 1 & 1.4 & 8 & 2 & 2.7 \\
Community support & 0 & 0 & 0.0 & 8 & 2 & 2.7 \\
Student organizations & 0 & 0 & 0.0 & 8 & 2 & 2.7 \\
Lab management & 0 & 0 & 0.0 & 9 & 1 & 1.4 \\
\hline
\end{tabular}


Equipment and Funding. The top two ranked problems indicated by both novice and veteran teachers were equipment $(72.5 \%)$ and funding $(72.5 \%)$. The most common response by both novice and veteran TE teachers was out-of-date or not enough equipment due to lack of funding. Examples of other responses included "updating shop to keep with industry standards," "maintaining equipment," and "obtaining and learning emerging software and equipment."

Discipline. The third most encountered problem (13.6\%) among novice respondents was discipline. Discipline was ranked sixth as a current problem (8.2\%). The most common response was "classroom management." Novice TE teachers comments included "finding the balance of being tough enough, but not too tough on students," and "dealing with inappropriate student behavior in labs." Statements by veteran TE teachers included "dealing with lazy students" and "streamlined support and consistency with discipline from my classroom to the office."

Not understanding what TE is. Nine respondents (12.3\%) indicated the image or not understanding what TE is was a problem for the novice teacher whereas, the problem decreased to $6.8 \%$ among veteran TE teachers. The most common statement was that "TE classes are a dumping ground for low ability students and uninterested students." Other statements included: "guidance counselors not knowing the technical knowledge needed and enrolling students with very low math and/or reading ability," "having parents, students, counselors, and administration understand what TE is," "academic teachers and administrators not understanding the academic application in TE," and "being questioned as to what is TE's exact function." A veteran TE teacher noted, "that even though I work with other CTE teachers, TE is very specialized, and topics such as equipment repairs was not readily understood nor accepted."

Undergraduate preparation. Undergraduate preparation ranked fifth among identified problems for novice teachers $(8.2 \%)$ while it was a non-issue for veteran TE teachers. Comments by novice TE teachers included "there is a discrepancy between what courses are offered and what I was prepared to teach," "learning from state-of-the-art equipment with all the tools and then going into the classroom with little-to-no modern equipment available," "how to work with IEPs and 504 plans," "not knowing how to teach differentiated learning, with the large number of students who are exceptional learners," "creating quality lesson plans," "about Perkins and CTE funds available," and "grading how to make effective rubrics."

Class Preps. Class preps ranked third among identified problem for veteran TE teachers $(15.1 \%)$ and was a lesser noted problem for novice teachers $(5.4 \%)$. The most common response was "teach too many preps [-6, 7, even 9 preps]." Other statements included "not enough time to prep and plan," "setting up shop takes many hours and can be overwhelming," "teaching multiple classes within one class period," and "dynamic teaching load - drafting, computer programming, tech lab, 3D printing, modern manufacturing all by myself in a small school." 
Administrative Support. Administrative support was within the top five veteran problems $(10.9 \%)$ but not as prevalent for novice teachers $(5.4 \%)$. Mutual problem statements included "lack of support," "always fighting for recognition and value of classes," and "lack of direction and expectations."

Differences between Novice and Veteran Teachers. Noticeable percentage differences between problems as a novice teacher and veteran teacher included number of class preps, time management, faculty relationships, and paperwork. Problems indicated for a novice TE teacher that were not as widespread among veteran teachers included understanding what TE is, which was $12.3 \%$ and declined to $6.8 \%$, and equipment, which decreased from $54.7 \%$ to $38.3 \%$. On the reverse, funding was a more notable problem for veteran teachers at $34.3 \%$ compared to $17.8 \%$ by novice teachers; administrative support increased from $5.4 \%$ to $10.9 \%$; and class preps increased from $5.4 \%$ to $15.1 \%$ as a veteran problem.

Several problems were mentioned by teachers at the beginning of their career that were not cited as problems for veteran teachers and vice versa. Early career problems included reputation of previous teacher $(8.2 \%)$, undergraduate preparation $(6.8 \%)$, mentorships $(4.1 \%)$, parents $(4.1 \%)$, paperwork $(4.1 \%)$, and knowing policy and procedures $(4.1 \%)$, whereas veteran problems that were not an issue among novice TE teachers included community support $(2.7 \%)$, student organization $(2.7 \%)$, and lab management $(2.7 \%)$.

\section{Discussion}

Problems Identified. Twenty-six problems identified by Illinois TE teachers have been reported in previous studies as problems more broadly among teachers. The findings in this study provide reference solely for TE teachers, offering school administrators and TE professionals' evidence on which to base retention efforts and professional development programs.

Interestingly, of the top five problems, three problems indicated for a novice teacher are still problems for veteran teachers. The top two problems for a novice and veteran TE teachers were equipment and funding. As with the AFT (2014), the results of this study aligned with the dominant challenges of equipment and funding across all CTE areas. Specific to TE, the problem of adequate funding has been a consistent issue for over three decades starting with Wicklein (1993) and Wicklein (2004), to the most recent study by Lazaros and Rogers (2006). Equipment and funding are centralized components to the TE curriculum. Teaching effectiveness is challenged as a result of working with "out-of-date equipment due to a lack of funding," as respondents referenced in this study. Furthermore, the findings indicate that programs not meeting industry expectations and standards due to the lack of resources and up-to-date equipment are not considered high quality. Essentially, programs which are not adequately funded nor have the appropriate equipment do not prepare learners with career skills necessary for the TE pathway.

Included in the top five challenges identified in this study was understanding the true nature of TE. Understanding what TE is was ranked fourth among novice TE teachers and placed fifth among veteran teachers. This noted problem has been an ongoing concern 
found in previous CTE and TE studies (Advance CTE, 2016; American Federation of Teachers, 2014; Lazarous \& Rogers, 2006; Lee, 2009; Wicklein, 2004; Wicklein, 1993). Respondents in this study have experienced inaccurate assumptions by school personnel and the general public as to what TE is. The negative or outdated image, being or feeling misinformed about the rigorous requirements in TE, and questioning the value of the TE all contribute to this repeatedly reported problem. As a result, the profession could be missing potential students to pursue a career in TE because of a false perception or not fully understanding about TE. This problem can be related to other problems noted within this study such as student motivation, administration support, faculty relationships, guidance counselor issues, and community support.

Discipline was indicated as more of a problem for novice teachers than for veteran teachers. Discipline was not identified in previous referenced studies. A plausible explanation for little problems related to discipline could be zero tolerance for misbehavior due to safety reasons as well as the task-oriented projects dictated by the curriculum. However, in this study, comments made by novice teachers such as "balancing how to discipline" and "how to deal with inappropriate behavior" were indicative of trying to find their own process of classroom management while veteran teacher comments alluded to student accountability and follow through by administration.

Some problems were identified for novice teachers but not veteran teachers, which included the reputation of previous teachers, undergraduate preparation, parents, paperwork, mentorships, and knowledge of policy and procedures. Learning the school culture and assimilating into the teaching profession is part of the induction phase, which can be daunting and overwhelming, all while maintaining the daily tasks of teaching. Johnson (2004) and Gaytan (2005) also found that school policy and procedures and working conditions (previous teacher and mentorships) were identified as retention factors for novice teachers. As teachers earn tenure and progress in their years of teaching, their mindset shifts to external forces such as community and administration support, which were identified as problems in this study for veteran TE teachers.

Problems as Motivator and Hygiene Factors. Applying the results to this study's theoretical framework, the problems can be classified as noted above into two categories based on Herzberg's (1966) theory: motivator (intrinsic) and hygiene (extrinsic) factors. According to Herzberg (1966), the problems identified can be located on the negative end of the two factors' respective continuums: no satisfaction (motivator's continuum) and dissatisfaction (hygiene's continuum). This means that both factor sets can contribute to unfavorable experiences for a teacher, thus decreasing their satisfaction level. Attempts to intervene to alleviate problems can shift the levels of satisfaction towards the positive ends of each factor's continuum. However, if the identified problems are not resolved, it could potentially impact teachers and cause them to leave the teaching profession.

For example, student motivation, which is considered a hygiene factor, was identified as a problem area, located on the negative end of the dissatisfaction continuum. If measures are taken, such as educating TE teachers about different motivational strategies to use or how to adapt content to the dynamics of the class, the motivation of students is no longer an explicit problem. Thus, the problem of student motivation slides to the positive end of 
Journal of Research in Technical Careers

the continuum. If nothing is done to correct the problem of student motivation toward TE, the problem stays at the negative end of the continuum, and according to the MotivationHygiene Theory, it is more likely the teacher will leave their teaching position.

Knowing the problems identified by TE teachers at the different career stages can assist school administrators and TE professionals to provide the needed support to address these problematic areas. By doing so, feelings of dissatisfaction can be inhibited, and teachers are more likely to stay in the profession.

\section{Limitations}

The findings for this research are limited to those teachers from Illinois who participated in the study. Therefore, the findings and conclusions cannot be generalized to other populations. Future studies might expand to regional and national TE teacher populations as well as replicate this study in a few years to determine if similar trends exist to gain more information regarding TE teacher retention.

\section{Conclusions}

Many TE teachers, due to dissatisfaction, leave the profession because of problems they face in their teaching assignments. This study identified problems of TE teachers at different career stages, both as novice teachers and veteran teachers. From the findings, 26 problems emerged of which three problems (equipment, funding, and understanding what $\mathrm{TE}$ is) identified by novice teachers were in the same top five for veteran teachers.

The challenges identified from this study could assist TE educators as they evaluate and revise curriculum in teacher education programs to adequately prepare and support its teacher candidates. For example, TE teacher educators need to ensure teacher candidates are prepared to teach with and without specific equipment, establish a working knowledge of how funding works and sources available, as well accommodations for exceptional learners with 504 plans and individualized education plans. TE professionals, such as TE professional organizations and state TE staff, can develop and coordinate in-service workshops and opportunities for professional development on topics based on the problems identified from this study. Alternatively, an advisory board that includes guidance counselors, administrators, other school counterparts, parents, and community employers can be established to align curriculum to workforce needs and in turn, a prime opportunity to educate and promote the importance of a TE program to these stakeholders.

An understanding of the concerns from novice and veteran teachers is a first step. Adequately preparing TE teachers and supporting experienced teachers to handle potential problems can increase job satisfaction and reduce teacher attrition in efforts to eliminate the national shortage of TE teachers. This research contributed to the body of scholarship established by Wicklein (1993) and followed the recommendation set forth to periodically research the challenges facing TE teachers, as well as keep the TE profession aware of needs and changing dynamics. 


\section{References}

Advance CTE. (2016, December). The state of career and technical education: Increasing access to industry experts in high school. Retrieved from https://cte.careertech.org/sites/default /files/files/resources/State_of_CTE_Industry_Experts_2016_0.pdf

American Federation of Teachers. (2014). The voices of career and technical education teachers: A report of The American Federation of Teachers 2014 Survey. Retrieved from https://www.aft.org/sites/default/files/cte_report_draft2.pdf

Ary, D., Jacobs, L. C., Razavieh, A., \& Sorensen, C. (2006). Introduction to research in education (7th ed.). Belmont, CA: Thomson Wadsworth.

Berns, R. G. (1990, December). The relationship between vocational teacher job satisfaction and teacher retention using discriminant analysis. Paper presented at the Annual Convention of the American Vocational Association, Cincinnati, $\mathrm{OH}$.

Boone, H., \& Boone, D. (2007). Problems faced by high school agricultural education teachers. Journal of Agricultural Education, 48(2), 36-45. https://doi.org/10.5032/jae.2007.02036

Cannon, J. G., Kitchel, A., Duncan, D. W., \& Arnett, S. E. (2011). Professional development needs of Idaho technology teachers: Teaching and learning. Journal of Career and Technical Education, 26(1), 32-47. https://doi.org/10.21061/jcte.v26i1.492

Clandinin, D., \& Long, J. (2015). Early career teacher attrition: Intentions of teachers beginning. Journal of Teaching Education, 26(1), 1-16. https://doi.org/10.1080/10476210.2014.996746

Cross, F. (2017). Teacher shortage areas: Nationwide listing 1990-1991 through 2017-2018. Washington, DC: United States Department of Education, Office of Postsecondary Education. Retrieved from https://www2.ed.gov/about/offices/list/ope/pol /ateachershortageareasreport2017-18.pdf

Cushall, S. (2002, May). Preparing with purpose: Discovering new directions in teacher education. Techniques: Connecting Education and Careers, 77(5), 20-21.

Dillman, D. A., Smyth, J., \& Christian, L. M. (2009). Internet, mail and mixed-mode surveys: The tailored design method (3rd ed.). New York, NY: Wiley and Sons.

Duncan, D. W., Ricketts, J. C., Peake, J. B., \& Uesseler, J. (2006). Teacher preparation and inservice needs of Georgia agriculture teachers. Journal of Agricultural Education, 47(2), 2435. https://doi.org/10.5032/jae.2006.02024

Garton, B., \& Robinson, J. (2006). Tracking agricultural education graduates' career choice, job satisfaction, and employability skills. Proceedings of the American Association for Agricultural Education Conference (pp. 552-563). Charlotte, NC. Retrieved from https://www.researchgate.net/publication/242073074_tracking_agricultural_education graduates\%27_career_choice_job_satisfaction_and_employability_skills

Gaytan, J. (2005). New business education teachers' experiences with teaching careers, professional culture, curriculum and assessment, and incentives and rewards. NABTE Review, $32,48-54$.

Heath-Camp, B., Camp, W. G., Adams-Casmus, Talbert, B. A., \& Barber, J. D. (1992). On becoming a teacher: An examination of the induction of beginning teachers in American public schools. Berkeley, CA: National Center for Research in Vocational Education.

Herzberg, F. (1966). Work and the nature of man. New York, NY: Thomas Y. Crowell Publishers.

Hughes, G. D. (2012). Teacher retention: Teacher characteristics, school characteristics, organizational characteristics, and teacher efficacy. Journal of Educational Research, 105(4), 245-255. https://doi.org/10.1080/00220671.2011.584922 
Illinois Association of Regional Superintendents of Schools. (2016). Illinois educator shortage crisis: Survey conducted by the IARSS. Retrieved from http://iarss.org/wp-content/uploads /2016/01/IllinoisTeacherShortage_12-10-15_kd-2.pdf

Joerger, R. M. (2002). A comparison of the in-service education needs of two cohorts of beginning Minnesota agricultural education teachers. Journal of Agricultural Education, 43(3), 11-24. https://doi.org/10.5032/jae.2002.03011

Johnson, D. (2004). Job satisfaction and intent to remain in teaching of Georgia business education teachers (Unpublished doctoral dissertation). University of Georgia, Athens, GA.

Layfield, K. D., \& Dobbins, T. R. (2002). In-service needs and perceived competencies of South Carolina agricultural educators. Journal of Agricultural Education, 43(4), 46-55. https://doi.org/10.5032/jae.2002.04046

Lazaros, E., \& Rogers, G. (2006). Critical problems facing technology education: Perceptions of Indiana teachers. Journal of Industrial Teacher Education, 43(2), 45-69. Retrieved from https://ir.library.illinoisstate.edu/cgi/viewcontent.cgi?article $=1182 \&$ context $=$ jst

Lee, L. (2009). Challenges and opportunities facing technology education in Taiwan. Proceedings of the International Conference on Technology Education in Asian and Pacific Region.

Self, M. J. (2001, December). On retention of secondary trade and industrial education teachers: Voices from the past. Paper presented at the 75th Annual Conference of the Association of Career and Technical Education, New Orleans, LA.

Stair, K., Warner, W., \& Moore, G. (2010, November). Identifying concerns of preservice and inservice teachers in agricultural education. Paper presented at the Annual Conference of the Association of Career and Technical Education Research, Las Vegas, NV.

Tamberg, M. B. (2006, October). Teacher to teacher: Teachers are using the Internet to find jobs and then keep them with online support from mentors and peers. Ed Tech: Focus on K-12. Retrieved from https://edtechmagazine.com/k12/article/2006/10/teacher-to-teacher

Ubom, I., \& Joshua, M. T. (2004). Needs satisfaction variables as predictors of job performance of employees: Implications for guidance and counseling. The African Symposium. An On-line Educational Research Journal, 4(3), 1-7.

Voke, H. (2002). Understanding the teacher shortage. ASCD InfoBrief, 2002(29), 1-17.

Wicklein, R. (2004). Critical issues and problems in technology education. The Technology Teacher, 64(4), 6-9. Retrieved from https://digitalcommons.usu.edu/cgi/viewcontent.cgi ?article $=1064 \&$ context $=$ ncete_publications

Wicklein, R. (1993). Identifying critical issues and problems in technology education using a modified-Delphi technique. Journal of Technology Education, 5(1), 54-71. https://doi.org/10.21061/jte.v5i1.a.5 